June - 2009

\title{
Creating Effective Collaborative Learning Groups in an Online Environment
}

\author{
Jane E. Brindley and Christine Walti \\ University of Oldenburg, Germany \\ Lisa M. Blaschke \\ University of Maryland University College, USA
}

\begin{abstract}
Collaborative learning in an online classroom can take the form of discussion among the whole class or within smaller groups. This paper addresses the latter, examining first whether assessment makes a difference to the level of learner participation and then considering other factors involved in creating effective collaborative learning groups. Data collected over a three year period (15 cohorts) from the Foundations course in the Master of Distance Education (MDE) program offered jointly by University of Maryland University College (UMUC) and the University of Oldenburg does not support the authors' original hypothesis that assessment makes a significant difference to learner participation levels in small group learning projects and leads them to question how much emphasis should be placed on grading work completed in study groups to the exclusion of other strategies. Drawing on observations of two MDE courses, including the Foundations course, their extensive online teaching experience, and a review of the literature, the authors identify factors other than grading that contribute positively to the effectiveness of small collaborative learning groups in the online environment. In particular, the paper focuses on specific instructional strategies that facilitate learner participation in small group projects, which result in an enhanced sense of community, increased skill acquisition, and better learning outcomes.
\end{abstract}

Keywords: Distance education; open learning; online learning; e-learning; collaborative learning; pedagogy; instructional design; learner motivation

\section{Introduction: The Challenge of Creating Effective Study Groups}

Online courses offer the opportunity to create a highly social learning environment, characterized by participation and interactivity for both students and instructors. According to Kearsley (2000), online learning is as much a social activity as an individual one. However, the quality and quantity of interactivity can vary dramatically from course to course. Swan (2001), citing a 
number of authors, identifies course design as a critical factor in determining the quantity, quality, and type of interactivity (learner interaction with content, instructors, or peers) in a course. Kearsley (nd) points to the importance of instructor skill in creating and managing interaction in online courses, particularly when collaborative learning is required. However, he also points out that most people have little formal training in how to successfully interact or work with others and that the social milieu of online activities is quite different from in-person interactions, thus requiring new skills and behaviors.

Engagement, defined as "student-faculty interaction, peer-to-peer collaboration and active learning..." (Chen, Gonyea, \& Kuh, 2008, para. 2), has been positively related to the quality of the learning experience. Social learning or learning as part of a group is an important way to help students gain experience in collaboration and develop important skills in critical thinking, selfreflection, and co-construction of knowledge. Online learners should not be impoverished in terms of social learning because they cannot or choose not to come to a campus. Access to education should not mean merely access to content (which is readily available without formal enrollment with an educational provider); rather, it should mean access to a rich learning environment that provides opportunity for interaction and connectedness. Quality learning environments include opportunities for students to engage in interactive and collaborative activities with their peers; such environments have been shown to contribute to better learning outcomes, including development of higher order thinking skills. Specific pedagogical benefits of collaborative learning include the following:

- Development of critical thinking skills,

- Co-creation of knowledge and meaning,

- Reflection,

- Transformative learning. (Palloff \& Pratt, 2005)

Different learning styles and cultures can be accommodated more easily because effective collaborative learning values diversity (Palloff \& Pratt, 2005). Further, skills gained from the experience of collaborative learning are highly transferable to team-based work environments (Shaw, 2006). Chapman, Ramondt, and Smiley (2005) also establish a strong link between building effective online communities and deeper learning and confirm that "... the world of work requires that learners can apply, analyse, synthesise and evaluate information...” (p. 220). Despite these documented benefits and the intense popularity of informal social networking using Web 2.0 tools and mobile devices, collaborative learning in the form of small groups (four to six peers), which is not of their own choosing, is often dreaded and avoided by online learners.

Online learners who seek flexibility in their study situations can view participation in group learning as an impediment to their progress and often balk at or at best tolerate collaborative learning situations imposed by course design. Students may have reservations about their ability to work as part of a group (Harasim, Hiltz, Teles, \& Turoff, 1998), or they may have become reluctant to participate based on negative past experiences of working with an unproductive or very difficult peer, having had to carry more than their fair share of the workload, or having received a grade that they felt did not reflect their level of contribution to a group project. 
One proposed method of ensuring learner participation in online collaboration is to demonstrate the value of group learning by assessing (defined here as assignment of a grade) both the product and process of group work (Swan, Shen, \& Hiltz, 2006). Swan et al. (2006) propose that "Assessment can be seen as the engine that drives student course activity, online or off. It is particularly important in encouraging and shaping collaborative activity online" (p. 45). This paper proposes an alternate perspective. The authors present data gathered over a three year period from a class in an international master of distance education (MDE) program that indicates that the introduction of grading has made no discernible difference to participation in study groups based on a straightforward comparison of participation rates between the graded and nongraded sections. Based on experience from this course and a model from another course in the same program where group work has never been graded, the authors propose alternative methods to encourage learners to experience the value of collaborative learning by creating study group experiences that are motivating and rewarding.

\section{Collaborative Learning and Connectivism}

Siemens (2005) proposes a contemporary theory of learning called connectivism that recognizes the impact of technology on society and ways of knowing. Although some writers have challenged both the need for a new learning theory and whether connectivism meets the parameters of theory (Kop \& Hill, 2008), Siemens provides a premise and a framework that are very useful for understanding collaborative learning in an online environment. From his viewpoint, learning in the digital age is no longer dependent on individual knowledge acquisition, storage, and retrieval; rather, it relies on the connected learning that occurs through interaction with various sources of knowledge (including the Internet and learning management systems) and participation in communities of common interest, social networks, and group tasks.

From this perspective, learning consists of retrieving information from self, others, and machines, collaborating to create knowledge, and applying information to current contexts. Hence, Siemens' (2005) learning theory is about individuals connecting with each other and with technology. Effective learners are those who can cope with complexity, contradictions, and large quantities of information, who seek out various sources of knowledge, and who can create and sustain learning communities and networks. According to Siemens (2005), learning ecologies (communities and networks) facilitate important information sharing and co-construction of knowledge while encouraging life-long learning in the individual as well as the group.

In a collaborative learning environment, knowledge is shared or transmitted among learners as they work towards common learning goals, for example, a shared understanding of the subject at hand or a solution to a problem. Learners are not passive receptacles but are active in their process of knowledge acquisition as they participate in discussions, search for information, and exchange opinions with their peers. Knowledge is co-created and shared among peers, not owned by one particular learner after obtaining it from the course materials or instructor. The learning process creates a bond between and among learners as their knowledge construction depends on each other's contribution to the discussion. Hence, collaborative learning processes assist students to develop higher order thinking skills and achieve richer knowledge generation through shared 
goals, shared exploration, and a shared process of meaning making (Brookfield, 1995; Christiensen \& Dirkinick-Holmfeld, 1996; Jonassen, Davidson, Collins, Campbell, \& Haag, 1995; Palloff \& Pratt, 2005).

Connectivism (Siemens, 2005) recognizes that in the online learning environment, seeking and constructing knowledge is most often accomplished through interaction and dialogue. The authors of this paper agree with Siemens and like most online educators acknowledge the importance of creating learning environments that promote group connectivity and collaboration experiences that help students to acquire the skills necessary to create and effectively participate in learning communities and social networks. The question that arises for online teachers is how to incorporate small group learning experiences into courses that are inviting and provide productive, engaging, and skill building spaces for learners, which encourage them to repeat the collaborative learning experience independently.

Siemens (2002) notes that learner-learner interactions in an e-learning course can be viewed as a four stage continuum:

\section{Communication}

People 'talking,' discussing

\section{Collaboration}

People sharing ideas and working together (occasionally sharing resources) in a loose environment

3. Cooperation

People doing things together, but each with his or her own purpose

4. Community

People striving for a common purpose

This continuum of involvement provides a useful framework for thinking about scaffolding with learners through progressively more complex interaction skills leading to the creation of an effective working group. Siemens (2002) proposes that in an online course, interaction will probably not go beyond communication/collaboration most of the time. He notes that while it is not realistic to expect community in many online courses, it should be possible in graduate level programs with high learner-learner contact. In the MDE program that provides the context for this paper, acquisition of skills associated with collaborative learning is an explicit goal. Courses have little static content, other than a comprehensive syllabus and course outline, and are heavily driven by interaction among learners and between instructor and learners. Small group projects are a common learning method, and discussion has intensified about the merits of grading students' collaborative group work as a means of motivating student participation. The study described in this paper is a form of reflective practice in that it considers the literature and data from the program for the purpose of informing these discussions. 


\section{Objectives and Research Hypothesis}

The initial objective of the study was to determine whether grading collaborative projects is positively related to higher student participation levels in small group work. The hypothesis leading to the research was that student participation levels would be higher in small group work where group projects were graded as compared to those where they were not graded. The results from the investigation of this main hypothesis led to a post-hoc research question about factors other than grading that might positively influence participation in collaborative learning in small groups. These factors are discussed in the latter half of the paper.

\section{Context and Methodology}

In January 2000, the University of Maryland University College (UMUC), USA, and Oldenburg University, Germany, began offering a joint online master's program, the Management of Distance Education (MDE). Courses within the program are provided online and delivered using UMUC's proprietary course software, WebTycho. WebTycho supports asynchronous dialogue using main conference threads as well as collaboration for smaller groups within a study group area using synchronous online chat and collaborative documents (See Figure 1).

Students in the MDE program are adults who have attained at least a baccalaureate degree and are generally between the ages of 30 and 50 (67\%); they are mainly from the United States, with a minority from other countries. Approximately $70 \%$ are female and $30 \%$ are male. Most are working full- or part-time (90\%). The classes from which the data was collected for the purpose of this study fit this profile (Porto, Bernath, \& Walti, 2006).

The Foundations of Distance Education (MDE 601) course is intended to provide graduate students with a foundation of the knowledge, skills, and attitudes required for them to become competent practitioners of distance education. This initial, introductory course to the MDE program has been offered continuously since 2000 during each university semester - spring, summer, and fall; at times, more than one section has been offered per semester. The course is structured into four modules with a main conference posting area for each module. Smaller study group areas with three to six students can be found in the study group conferences, which are only accessible by the instructor and the student members of the respective study group. 


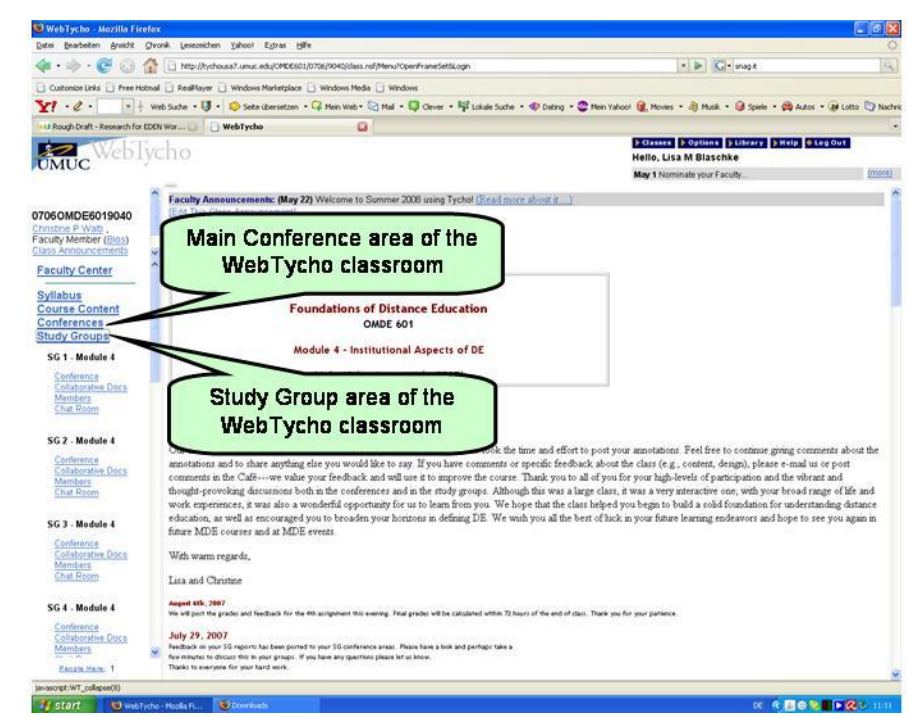

Figure 1: WebTycho conferences and study group areas.

The MDE 601 course includes two study group projects:

1. In the first module, students collaborate within their individual study groups to articulate and present a group definition of distance education.

2. In the fourth module, students select and/or define a typology of distance education institutions (e.g., dual-mode and single-mode institutions) and then conduct research on institutions that meet the schematic defined for the typology. They then present the results of their collaborative efforts in a group paper.

Data was gathered from fifteen sections of MDE 601, from 2005 to 2008. The collaborative work in module1 has never been graded and the collaborative work in module 4 of the first 13 sections of the course offered during the period covered by this study (spring 2005 to summer 2007) was not graded. However, during this time detailed instructor feedback for group projects was provided. In the sections of fall 2007 and spring 2008, faculty began to assign a formal grade after repeated requests by students to have this second group project graded. The group projects were then assigned a cumulative grade based on the following: 1) the collaborative group process, 2) the final product (group paper), and 3) peer-to-peer evaluation of the collaborative work.

During the period for which data was collected, the number of students within a course section ranged from 13 to 35, with an average of 20 students per section, and the study groups comprised on average four to five students each. The content and instructions for the collaborative group project assignments in modules 1 and 4 were consistent over this period.

For the purposes of the study, the following data was collected for each of the 15 course sections:

1. number of students,

2. number of posts in each study group area during each of module 1 and module 4 . 
Calculations were made for each course section as follows:

1. total number of posts in both study group areas (module 1 and module 4),

2. percentage of posts in module 1 compared to total posts for both study group areas,

3. percentage of posts in module 4 compared to total posts for both study group areas,

4. average number of posts per student during each of module 1 and module 4 ,

5. comparison (by multiple) of number of posts in module 4 compared to module 1 .

All of these figures are presented in Table 1.

\section{Findings}

When comparing study group behaviour between module 1 and module 4 within each course section, it was found that participation levels during the second study group project were on average 2.05 times the participation levels for the first study group project when neither module was graded (see Table 1). This finding for sections where neither group project was graded (spring 2005 to summer 2007) was expected because the study group project in module 4 is significantly more complex and work-intensive than the project in module 1 , requiring more interaction among group members. It was expected that there would be noticeably more study group activity (> 2.05 times that in module 1) during the second study group project once instructors initiated grading for that project. However, this was not the case. When the second group project was graded (fall 2007 and spring 2008), participation levels during the second study group project were on average 1.93 times the participation levels during the first study group project.

To further control for the varying levels of participation (activity as measured by \# of postings) that naturally occur between course sections, participation levels between graded and non-graded sections of the course were compared by considering the level of activity within module 4 in the context of total activity in both modules within each section of the course. The initial findings in fall 2007 did not support the original hypothesis that participation levels would increase when the module 4 project was graded; these findings were further reinforced in spring 2008. In both of these sections, which had a grade assigned to the second study group project, student participation levels remained consistent with those in previous sections where there had been no grading. In other words, in a straightforward comparison of participation levels as measured by percentage of postings in module 4 (\# of postings in module 4 study group area/total \# of postings in both study group areas), there was no discernible increase or decrease in participation levels when a grade was assigned in comparison to student participation levels in the thirteen previous offerings of the course when a grade was not assigned to the group project (see Table 1 and Figure 2). These preliminary findings do not show an immediate benefit in assigning grades to the collaborative study group project, but this is based on only two sections of the course that have had graded projects. A greater number of cohorts and a more extensive statistical analysis are required before any firm conclusions can be reached. 
Table 1: MDE 601 Research Data - Participation Levels [15 Cohorts (2005-2008)]

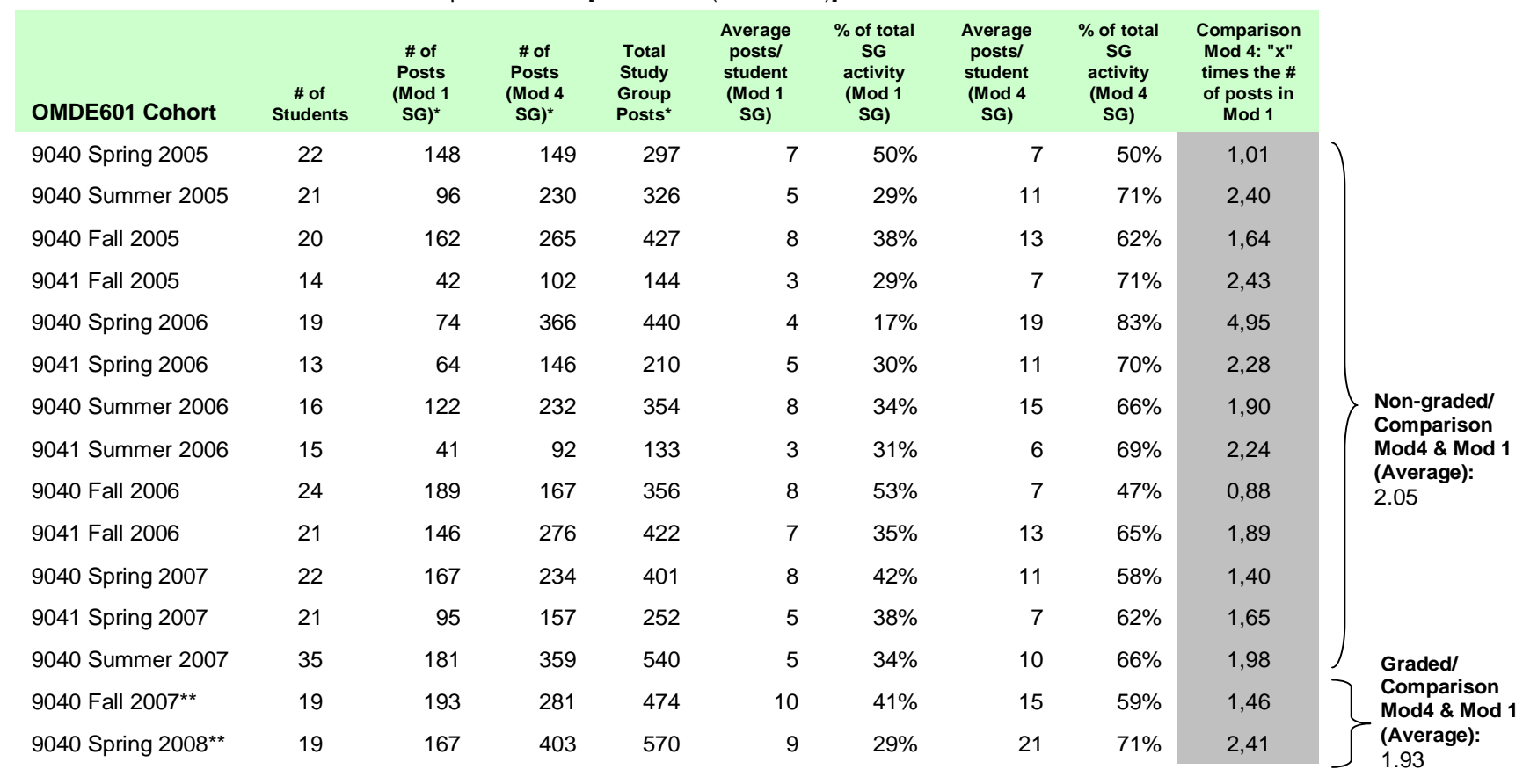

* Numbers do not include instructor postings or collaborative documents

${ }^{\star *}$ Courses where Module 4 study group project was graded

Figure 2: MDE 601 - Module 4 as a percentage of total group activity.

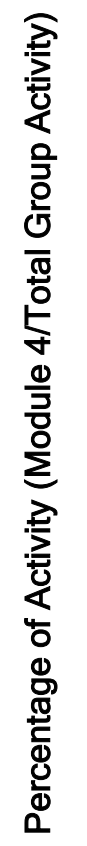

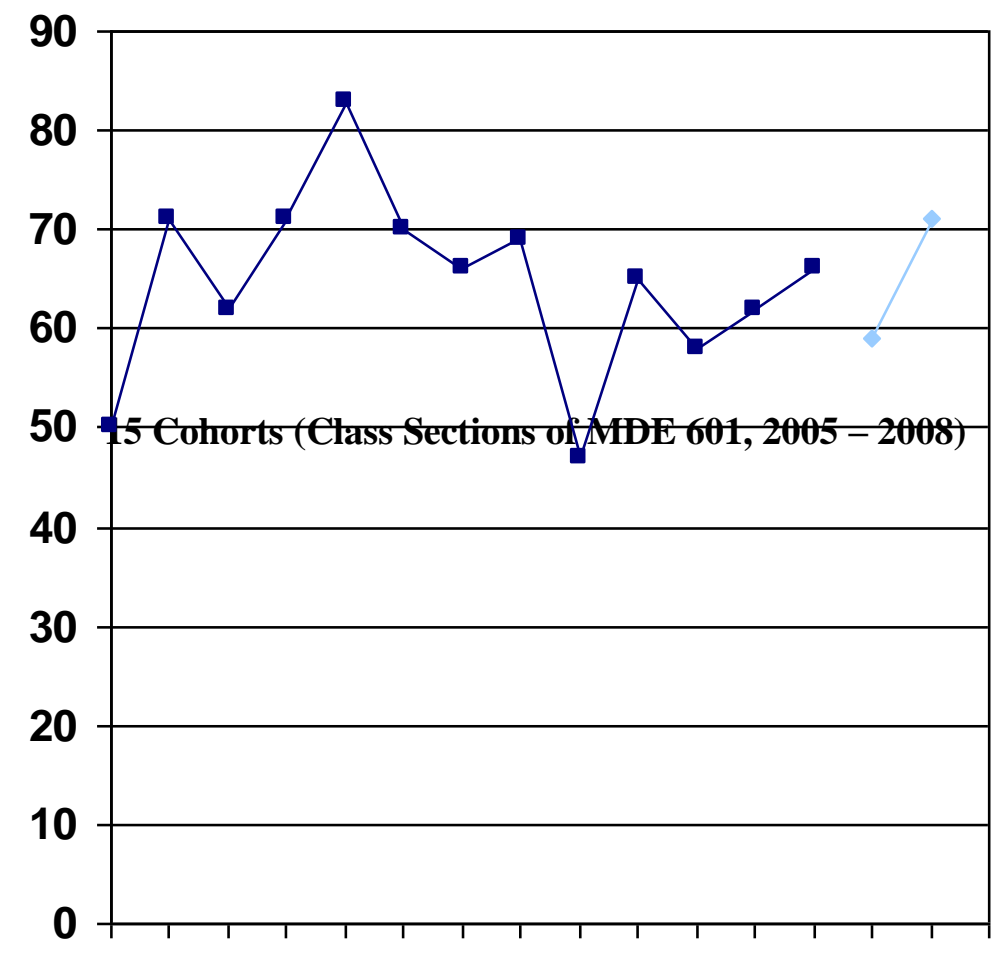


In addition to the main findings, it was revealed that in general students participated more in study groups than in the larger main conferences. So-called "witness learners" (Beaudoin, 2003), those who never appear in module conference discussions, almost always actively participate in study group activities even when the group work is not graded. It could thus be concluded that some students prefer small group interaction to interaction within larger class conferences; however, additional research would be necessary to further support this claim. Based on the preliminary data, it was also hypothesized that although students may have the will to participate in collaborative projects, the skills to effectively engage in online collaboration are often lacking. In the case of MDE 601, this could well be the case because this course is often the first online study experience the students have undertaken within the MDE program, and they have not yet developed the necessary skills to collaborate effectively online.

As a result of the preliminary findings, a post-hoc question of what other factors in addition to grading might contribute to encouraging participation in small group study projects was posed. The authors decided to consider MDE 608, a required course in the MDE program where group work has never been graded (at the request of students) but where participation levels in the study group project are consistently high. The authors do not offer it as a direct comparison with MDE 601 (comparable data is not available) but rather as a case study of a course where strategies identified in the literature as encouraging participation in small groups have been explicitly employed with success. In fact, a number of the strategies used in MDE 608 are also used in MDE 601, and this may, in part, account for the lack of increase in participation rates in MDE 601 study groups when grading was added as additional inducement. It should be noted that high participation levels in MDE 608 study groups (which can be verified by data) may be due, at least in part, to students having more study group experience by the time they reach this advanced course.

\section{An Alternative Model for Effective Collaborative Learning - MDE 608}

The Learner Support in Distance Education and Training course (MDE 608) is a required course in the MDE program but can be taken at any time prior to graduation. Most students who take the course have completed at least MDE 601. Hence, the students who take MDE 608, relative to those in MDE 601, generally have more experience as online learners. The overall objective of MDE 608 is to help students develop the knowledge and skills to be able to assess learner needs and contextual demands in order to plan and implement appropriate learner support for a particular situation. The course is designed so that students acquire basic knowledge of the field of learner support and, at the same time, are given assignments that help them to build increasingly complex skills (e.g., critically analyzing literature, articulating a position and supporting it with references to the literature, working in a small group to do an environmental scan and needs assessment in a particular education or training context, applying their knowledge in designing a learner support system for a particular context).

As with other MDE courses, study groups (small groups that work collaboratively on a project) are an integral part of the instructional design. Although a small portion (10\%) of the overall grade in MDE 608 is awarded for overall participation in the course, the projects completed by 
the study groups are not graded. The course has been offered for 7 years and during that time the study groups have enjoyed full participation with rare exceptions, usually due to unusual circumstances, supporting the findings from MDE 601, which revealed no significant relationship between grading and participation. MDE 608 has used other means of valuing and encouraging participation in the study groups that are built into the design of the course. A thoughtful examination of this course in the context of the research questions posed by this paper suggest that these strategies contribute significantly to the effectiveness of the study groups both in participation levels and the quality of work produced by the study groups, which tends to be quite high.

The strategies employed in the course to both communicate the value of collaborative learning and to increase motivation to participate in the study groups in MDE 608 were identified as follows:

\section{Transparency of expectations}

Details of the requirements to participate in a study group are posted in the course syllabus. The purpose (learning objectives) of collaboration and expectations of the learners are made very clear in the main conference. If students communicate reluctance about study group participation, instructors encourage participation and are open about discussing the purpose and process.

\section{Clear instructions}

The group task, timelines, and usability of the desired product are described in detail, giving students the best opportunity to focus on collaborating to share ideas and the workload rather than leaving them to spend a great deal of time trying to clarify the task and develop a common understanding of it.

3. Appropriateness of task for group work

Each study group works as a team of consultants to carry out an environmental scan and needs analysis of a particular educational or training provider (develop a case study) in preparation for a second task (done individually). This type of task is easier and a much more rich experience when performed by a group as opposed to an individual.

\section{Meaning-making/relevance}

The group assignment is an opportunity to apply principles and knowledge gained in the course to the analysis of a real life situation, often from a student's work context. Further, in the last week of the course, the group projects are exchanged and peer reviewed (by the groups), making full use of the learning potential of the project.

\section{Motivation for participation embedded in course design}

Individual success is dependent upon group success. The group product (comprehensive case study) is needed by individual learners in order to complete their final assignment, that is, to design a learner support system for their group's case study. 


\section{Readiness of learners for group work}

The group project takes place during the final third of the course after students demonstrate that they have sufficient mastery of the subject matter to reflect on how to apply their knowledge in particular contexts, including their own work settings (as demonstrated in the conference discussions), and they have had the opportunity to develop a sense of community and hone their collaborative learning skills.

\section{Timing of group formation}

Although the group project is not undertaken until the third section of the course, the study groups are formed during the second unit. This allows time for a sense of collaboration and interdependence to develop among the members before the task is assigned. During the period before the task, group members discuss their shared interests and possible scenarios for the case study.

\section{Respect for the autonomy of learners}

Study group participation is mandatory but learners have the freedom to form their own groups based on shared interests. Instructors provide guidelines for group formation and open a space in the virtual classroom for this purpose. The choice of educational or training context for the case study is the decision of each group, and groups often have lively discussions and do significant research before consensus is reached, resulting in high ownership of the project.

\section{Monitoring and feedback}

The study group conferences and chats are monitored closely by instructors who provide respectful and timely feedback on process and direction when necessary to prevent groups from getting stalled or going off course. Instructors also provide feedback on draft versions of the case studies and provide time for revisions before presentation of the final project.

\section{Sufficient time for the task}

Most of the third and last unit of the course (approximately four weeks) is devoted to the study group project to provide sufficient time for the process and to accommodate varying work schedules and time zone differences of these adult learners.

Course evaluations from MDE 608 consistently reveal learner satisfaction with the course and with the study group experience. Occasionally, one member of a study group does not pull his or her weight but this is the exception rather than the rule, and in most cases the groups organize themselves relatively quickly and all learners contribute fairly equally to the task. Grading the study group project would not only undermine the values and motivational aspects of the course design but based on the data gathered in MDE 601 would not have a positive impact in terms of participation by learners or the quality of the work presented by the groups. Further, most students have a very positive reaction to not having their group work graded. From the experience in this course, it appears that instructional strategies can be an effective motivational tool to encourage participation and to enhance collaborative learning in small groups and a positive 
alternative to using grading as an incentive. As well, instructional strategies such as the ones described herein provide students with a positive experience of group work and contribute to learner autonomy and self-direction.

\section{Implications for Practice}

Based on these findings from MDE 601 and MDE 608, the authors propose that rather than focus on the grading of collaborative group projects, instructors should incorporate a variety of instructional strategies to improve the quality of group collaboration and to increase the likelihood of student participation. These strategies are outlined below:

\section{Facilitate learner readiness for group work and provide scaffolding to build skills} Scaffolding is important in preparing learners for small group projects. This can be accomplished through instructional design (sequencing activities within the course that build on previously learned skills) and positioning small group activity later in the course when students have acquired the confidence and skills to be successful. Students need to be taught the necessary skills for effective online collaboration, particularly those skills that will help them succeed in a group environment, such as planning and negotiation skills (Curtis \& Lawson, 2001). Chapman, Ramondt, and Smiley (2005) recommend using ice breakers, seeding, and statements about expectations regarding participation, etiquette, and guidelines for behaviour, and Smith (2003) discusses uses of interaction standards, tools, and techniques. Learners often need help with acquiring information literacy skills (how to retrieve, evaluate, apply, and source information effectively) and with using the technology effectively.

\section{Establish a healthy balance between structure (clarity of task) and learner autonomy} (flexibility of task)

The instructor should provide guidelines for team member performance in conducting the group project (Palloff \& Pratt, 1999) and ensure that the task is achievable, sustainable, and properly timed within the course (Bouchat, 2007). Juwah (2006) has found that allowing learners to form their own groups and select their own topics facilitates socializing within groups and positive group dynamics. Effective course design will make the purpose and parameters of group tasks and the learning goals clear and explicit while still allowing students flexibility, such as choice of group membership, member roles, and specifics of the topic. When students have personal control over the task (content, process, intentions, goal setting, consequences, outcomes, group partners), their engagement, responsibility, and sense of the relevance of the task are heightened.

\section{Nurture the establishment of learner relationships and sense of community}

In order for true collaboration to occur, a sense of community needs to be established within groups (Palloff \& Pratt, 2005; Chapman, Ramondt, \& Smiley, 2005). Important elements for establishing successful learning communities are informality, familiarity, honesty, openness, heart, passion, dialogue, rapport, empathy, trust, authenticity, disclosure, humour, and diverse opinions (Chapman, Ramondt, \& Smiley, 2005). 
Instructors can model, discuss, and reinforce these elements in the main conference, helping students to prepare for smaller, more intense group learning experiences. If students develop relationships with their peers early, they can build on these relationships in group work.

\section{Monitor group activities actively and closely}

During the collaborative process, the instructor needs to be available for feedback, general information, and private counsel. In addition, the instructor needs to intervene as required to keep discussions on track, support and animate dynamic conversation, help students stay focused on the task, assist with relationship building, and provide reassurance. Although this paper does not advocate formal assessment, continuous feedback is a type of formative evaluation that helps students develop specific skills and deepens the learning process.

\section{Make the group task relevant for the learner}

Research by Curtis \& Lawson (2001) has found that the more interested a student is in a group topic, the more motivated the student is in participating in the collaborative effort. Allowing learners to pursue topics according to mutual interest sets groups up to share and co-create knowledge. Authentic, real-world environments and relevant content provide motivation for collaborative learning. Enabling students to control and direct their learning to the greatest extent possible helps them to achieve a purpose that is specific to their needs and challenges their zone of proximal development (Vygotsky, as cited in Lin, 2008).

6. Choose tasks that are best performed by a group

Individual learners make compromises regarding flexibility of study in order to participate in a collaborative exercise. Engaging in tasks that benefit from teamwork will increase their sense of purposefulness and motivation to participate.

\section{Provide sufficient time}

Course design should allow sufficient time for collaborative learning activities, including time for scheduling, planning, and organizing. Most importantly, time is required for the discussion and exchange of ideas that are crucial to deeper learning.

\section{Some Further Thoughts on the Realities of Online Teaching and Learning}

Occasionally, despite best efforts in course design and instruction, a group will have low participation by some group members and/or low quality outcomes in terms of the interchange/discussion and the final product. It is important to recognize that there are a number of circumstances and factors that can contribute to a lack of participation and/or dysfunction within the virtual classroom and particularly within small groups. These can sometimes be mitigated by the instructor but their presence is often beyond his/her control. Learners who choose online study most often do so because of the flexibility and convenience of choosing their 
own study hours, usually because they have very busy lives. Particularly in the case of adult learners, other roles may be primary to that of student. Academic work is important but must fit around demands of career, home, and community. Group projects require that learners be present on a particular schedule, reducing the flexibility and convenience factor in online study and may cause anxiety and/or resentment, particularly if the purpose of the group work is not clear and the group experience is not positive.

Although most adult learners manage their multiple roles fairly effectively, unexpected events such as illness, a death in the family, or other changes in their personal circumstances can tip the balance and prevent them from being online over extended periods of time. A singular event such as a statutory holiday, a world cup soccer game, or a natural disaster may adversely affect short and longer duration discussions (Bouchat, 2007). Obviously, absences from small groups have a more profound impact than absences from the general conferences.

Students who are assigned a group project without an adequate level of readiness and/or guidance may be set up for failure. An interesting factor discussed by Sanders (2008) is that students are often ill-equipped through their previous educational experiences to collaborate (in general) or peer-review and often see colleagues as rivals. In such cases, peer reviewing (a common task for small group collaboration) is often superficial, unhelpful, and/or judgmental. It takes time to establish community, and 12 weeks (the common length of a semester in a paced program) is sometimes insufficient for those new to online learning to develop both the requisite skills and confidence to fully participate in collaborative learning.

The accessibility of technology to individual members of a group and each learner's skill level in using the medium can support or hinder a positive collaborative dynamic in that the technology can be the source of either frustration or motivation. There are also indications that the asynchronous format hinders the negotiation of difficult issues and conversations that require quick, direct turn-around. Confusion and breaks in communication can result from the delays between initial postings and responses that characterize asynchronous communication. Tools more suitable to collaborative learning (wikis, social bookmarking, RSS, and Skype) are readily available on the Internet but are not necessarily introduced to learners or incorporated into virtual classrooms in a systematic way.

The most effective learning is transformative but the required adjustment may temporarily disrupt a learner's ability to effectively collaborate with his/her peers. Lin (2008) posits that “... adult learning is not always joyful or motivated by heart-felt needs..." (p. 4) and notes that adult learners commonly experience anxiety over the gap between old thinking and new knowledge or capability as well as a sense of disconnectedness at various stages of the learning process.

Groups are comprised of individuals with unique personalities and learning styles and differing levels of skill. Personalities can clash, group leadership may be lacking or dominant, or there can be dysfunction and/or conflict within the group. For example, there are sometimes students who have a low commitment to the class for personal reasons. At the same time, they may not be ready to drop the course, and no amount of effort by instructors may increase their participation 
or commitment. Alternatively, there are occasionally students with difficult interpersonal styles, who can have a negative impact within their team. In these cases, it is sometimes best to encourage the group members to carry on without being overtly critical of the non-functioning member. Students pick up on the instructor's sensitivity to the situation and will usually respond by doing what they can to complete their group project. Handled in a constructive and positive way, this can present a good learning experience for all of the students including the ones who are low performers.

Finally, the dissatisfaction and reluctance that students express over mandatory participation in group projects often result from a sense of not having full control over the quality of the project and the subsequent grade assigned, particularly when someone in the group has less than satisfactory performance. This may be a good reason for not placing emphasis on grading as much as helping students to learn the skills of collaboration, including how to deal effectively with group members who are unable or unwilling to participate fully in the group process. If the right environment is created, both high performing and low performing students are able to reflect on and articulate their opinions about their experience and the outcomes of their learning. That being said, it is important to acknowledge the extra time and special skills required of instructors to ensure the effectiveness of small group learning experiences. Research appears to confirm that small group collaboration online needs careful management by the instructor (cf. Swan, Shen, \& Hiltz, 2006, p. 51).

\section{Limitations of the Study}

The sample for the main research question consisted of all students in the MDE 601 classes (the mandatory Foundations course of the MDE program) offered between 2005 and 2008, and for the post hoc question all students in the MDE 608 classes between 2000 and 2008, and as such is representative of the larger population of MDE students in the UMUC/Oldenburg online program. The MDE program population is similar to that of a number of other North American online university programs catering to working adults (i.e., in terms of characteristics such as age, gender, employment status, cultural diversity). That being said, this investigation of the effect of grading on participation in small study groups was only preliminary. Cross program and cross institutional studies with larger sample sizes are required in order to perform formal statistical analyses to confirm whether grading makes a significant difference to participation levels in online study groups. Evaluative research is also needed to test the efficacy of the suggested instructional strategies to increase participation in and satisfaction with small group learning, and further investigation is required to better understand and test the interactional effects among variables.

\section{Summary}

There appears to be a strong argument for including small group collaborative learning experiences in online courses. The literature reveals a significant relationship between participation in these experiences and deeper learning as well as the development of learning and teamwork skills. Further, collaborative learning appears to increase a sense of community, which 
has been shown to be closely linked to learner satisfaction and retention. However, the preliminary data collected in MDE 601 does not support a strong reliance solely on assessment (assignment of a grade) of group work to encourage participation in study groups. Although assessment may enhance participation for some students, observations of the methods used in MDE 608 and 601 and the authors' combined experiences of guiding students' collaborative efforts in the online classroom suggest that other factors, in particular instructional strategies, accomplish the same goal, perhaps more effectively and with added benefits for the learner.

This paper reinforces the importance of reflective practice for instructors. Assumptions about what impact specific strategies have on learner behaviour need to be tested constantly. In this case, it appears that instructional strategies may be equally or more effective than assessment in encouraging participation in small group activities in the online classroom. Further, well planned instructional strategies that are intended to improve the group learning experience appear to have a number of added benefits, such as helping students to achieve deeper learning and to build their confidence and skills. Further data collection and analysis are required to provide more conclusive evidence of the impact of grading on participation behaviour in online groups, but this preliminary investigation points to the need to continue to study this relationship. Future studies are also recommended to examine the impact of instructional strategies and assessment on the quality of group projects and the effectiveness of using journaling and e-portfolios in evaluating the impact of group work on learning outcomes. 


\section{References}

Beaudoin, M. (2003). Learning or lurking? Tracking the 'invisible' online student. In U. Bernath \& E. Rubin (Eds.), Reflections on teaching and learning in an online master program (pp. 121-130). Oldenburg: Bibliotheks- und Informationssystem der Universität Oldenburg.

Bouchat, C. (2007, December 17). Threaded discussion tips for designers. Learning Solutions eMagazine. Retrieved January 31, 2008 through personal subscription to The eLearning Guild.

Brookfield, S. D. (1995). Becoming a critically reflective teacher. San Francisco: Jossey-Bass.

Chapman, C., Ramondt, L., \& Smiley, G. (2005). Strong community, deep learning: Exploring the link. Innovations in Education and Teaching International, 47(3), 217-230.

Chen, P., Gonyea, R., \& Kuh, G. (2008). Learning at a distance: Engaged or not? Innovate, 4(3). Retrieved February 26, 2008, from http://www.innovateonline.info/index.php?view=article \&id=438\&action=article

Christiensen, E., \& Dirkinick-Holmfeld, L. (1995). Making distance learning cooperative. Retrieved May 19, 2008, from http://vbn.aau.dk/research/making_distance_learning_collaborative(125626)/

Curtis, D. D., \& Lawson, M. J. (2001). Exploring collaborative online learning. Journal of Asynchronous Learning Networks, 5(1), 21-34.

Harasim, L., Hiltz, S. R., Teles, L., \& Turoff, M. (1998). Learning networks: A field guide to teaching and learning online. Cambridge, MA/London, England: The MIT Press.

Jonassen, D., Davidson, M., Collins, M., Campbell, J., \& Haag, B. (1995). Constructivism and computer mediated communication in distance education. American Journal of Distance Education, 9(2), 7-25.

Juwah, C. (2006). Interactions in online peer learning. In R.C. Sharma \& C. Juwah (Eds.) Interactions in online education. Implications for theory and practice (pp. 171-190). New York: Lawrence Erlbaum.

Kearsley, G. (2000). Online education: Learning and teaching in cyberspace. Belmont, CA: Wadsworth.

Kearsley, G. (nd). Tips for training online instructors. Retrieved May 26, 2008, from http://home.sprynet.com/ gkearsley/OItips.htm 
Kop, R., \& Hill, A. (2008). Connectivism: Learning theory of the future or vestige of the past? International Review of Research in Open and Distance Learning, 9(3). Retrieved January 20, 2009, from http://www.irrodl.org/index.php/irrodl

Lin, L. (2008). An online learning model to facilitate learners' rights to education. Journal for Asynchronous Learning Networks, 12(1). Retrieved May 17, 2008, from http://www.distanceandaccesstoeducation.org/Results.aspx? searchMode=3\&criteria=en

Palloff, R. M., \& Pratt, K. (1999). Building learning communities in cyberspace: Effective strategies for the online classroom. San Francisco, CA: Jossey-Bass.

Palloff, R. M., \& Pratt, K. (2005). Collaborating online: Learning together in community. San Francisco, CA: Jossey-Bass.

Porto, S., Bernath, U., \& Walti, C. (2006). MDE program self-assessment report for the EFMD CEL accreditation. Oldenburg, Germany. http://www.c31.unioldenburg.de/literat/EFMDfinalrevised.pdf

Sanders, M. (2008, Feb. 18). A failure to collaborate. The Chronicle of Higher Education. First Person. Retrieved February 18, 2008, through personal account.

Siemens, G. (2005). Connectivism: Learning theory for the digital age. International Journal of Instructional Technology and Distance Learning, 2(1), January 2005. Retrieved May 25, 2008, from http://www.itdl.org/Journal/Jan_05/index.htm

Siemens, G. (2002). Interaction. E-Learning Course. October 8, 2002. Retrieved May 19, 2008, from http://www.elearnspace.org/Articles/Interaction.htm

Shaw, S. (2006). New reality: Workplace collaboration is crucial. Eedo Knowledgeware Whitepaper. Retrieved through personal subscription.

Smith, L. (2003). Assessing student needs in an online graduate program. In U. Bernath \& E. Rubin (Eds.), Reflections on teaching and learning in an online master program - A case study (pp. 255- 265). Oldenburg: Bibliotheks- und Informationssystem der Universität Oldenburg.

Swan, K. (2001). Virtual interaction: Design factors affecting students' satisfaction and perceived learning in asynchronous online courses. Distance Education, 22(2), 306-331.

Swan, K., Shen, J., \& Hiltz, S.R. (2006). Assessment and collaboration in online learning. Journal of Asynchronous Learning Networks, 10(1), 45-62. 